\title{
Fun As Serious Business: Creating A Fun Work Environment As An Effective Business Strategy
}

Kellmeny Jeffcoat, Baker College

Jane Whitney Gibson, (Email jwgibson1 @aol.com), Nova Southeastern University

\begin{abstract}
This paper discusses the use of fun in the workplace as an effective business strategy for recruiting and retaining talented employees as well as developing their creativity and productivity. The benefits of fun in the workplace are discussed and a few cautions are offered. Suggestions are made on creating a fun working environment using the "Be a Pal" model: Pay for fun, Allocate time for fun, and Lead the way.
\end{abstract}

\section{INTRODUCTION}<smiles>[AlH2]</smiles>

urely most people over the age of 18 will agree that work is serious business. When you grow up, you put away childish things and you go to work. Children have fun. Adults are productive and go about the business of earning a living and accomplishing their personal and family goals. With any luck, they find a job that brings them personal satisfaction and maybe some enjoyment. Too often, however, there is a disconnect between the joy and exuberance of youth and the daily routine of earning a living. Few organizations have not been impacted by the layoffs and economic downturn of recent years which have left many employees feeling lucky they are employed, no matter how unexciting the job may be.

There is room to suggest, however, that creating a fun working environment is an effective business strategy for the organization as well as the individual. Not only do employees benefit from a fun work environment, but the organization experiences powerful results as well. According to HR Focus, businesses that encourage fun in the workplace enjoy lower levels of absenteeism, greater job satisfaction, increased productivity and lower levels of downtime. (Hemsath, 1997). Recent books with titles like Joy at Work (Bakke, 2005) and Fun is Good: How to Create Joy \& Passion in Your Workplace and Career (Veeck \& Williams, 2005) illustrate the interest in the subject

This article advocates fun as an effective business strategy by examining the personal benefits, the organizational effects, and the cautions associated with having fun in the workplace. It also provides guidelines for creating a fun working environment.

\section{FUN AS AN EMPLOYEE BENEFIT}

Employees who have a good time at work enjoy physical benefits akin to the old adage, "laughter is the best medicine." In fact, laughter reduces stress, increases respiration and circulation and delivers more oxygen to the brain. "Laughter works as a kind of internal aerobics, and some consultants recommend that a person should laugh at least 20 times a day. (Filipczak, 1995, 48) From a slightly more scientific perspective,

Research has revealed that chemicals such as endorphins, epinephrine, and adrenaline are released in the body when individuals are having fun. That increases their energy and sense of well-being .. Laughter and fun can lower stress and its related health effects, such as heart disease, digestive problems and susceptibility to colds." (All work and no play..., 1997, 254) 
Joel Goodman, director of the consultancy organization, The Humor Project, teaches that humor is a coping mechanism. When a person laughs, "the immune system is given a boost, stress-related hormones such as cortisol are reduced, and our respiratory systems are improved." (Santosus, 2005, 2) Given these personal benefits to the employee, what can the organization gain from fostering a fun environment?

\section{FUN IN THE WORKPLACE}

We can look at fun in the workplace in terms of at least three strategic factors: recruitment and retention of excellent employees, increased creativity, and improved profitability.

\section{Recruitment And Retention}

Recruiting and retaining a quality workforce is a key strategy for any organization. A fun work environment can help in recruiting and retaining the most talented associates (Mariotti, 1999) Encouraging fun in the workplace helps to foster an environment that attracts workers to the organization and makes them want to stay.

Fun is a word repeatedly heard by Fortune Magazine when compiling its "100 Best Companies to Work for in America" list. Fortune scores companies in terms of credibility, respect, fairness and pride/camaraderie. One third of their evaluation relies on their own observations and the other two-thirds rely on a random survey of employees asked about management, job satisfaction and camaraderie among other things. Large, medium, and small companies alike said fun at work was one of the key variables in a successful company. Here are some typical examples. (Levering \& Moskowitz, 2005)

Among the largest companies, the Cisco employees loved the "nerd" luncheons where executives give talks about technical topics as well as the movie-themed food they enjoy on Academy Award day. Midsized companies that highlighted fun were SAS Institute, a software company whose gym contains pool, ping-pong, billiards, volleyball, and soccer; and Hot Topic whose 7,000 employees work for a CEO who sports orange streaks in his hair and where workers are encouraged to dress like rock stars. Specializing in teen apparel, Hot Topic pays for employees to go to concerts as long as they write up a fashion report afterwards.

Among small companies, employees of Adobe Systems enjoy private offices, a farmer's market, basketball and bocce courts and a full fitness center with trainers. The employees at Griffin Hospital share some pretty neat facilities with patients - family kitchens, strolling musicians, and chair massages. The employees at Stew Leonard's grocery stores have fun at pie-eating contests, hayrides and ski trips while the civil engineering firm, Kimley-Horn and Associates has a VP of Fun at each office.

While not included in the Fortune survey, Southwest Airlines can arguably be used as the best example of a well-known company whose culture is based on having fun. Their annual mottos such as "Still having fun after all these years," help explain why in 2004, Southwest was able to hire a little over 1700 employees out of almost 226,000 applications. (http://www.southwest.com/about_swa) Fun in the workplace is an essential component in creating an atmosphere conducive to recruiting and retaining employees. Says one researcher, "In short, if you're having fun at work, then you like your job, and you're probably good at it." (Santosus, 2005, 2)

\section{Increased Creativity}

According to Dennis Bakke, CEO of AES and author of Joy at Work, the amount of fun in an organization is roughly equivalent to the number of people involved in decision-making. Seemingly, fun and creativity are interrelated. Fun in the workplace inspires and fosters creativity and can help a company gain or maintain a competitive edge. In fact, recreation and creativity both originate from the same Latin word, "creare", which means to create. (Mariotti, 1999). Having a sense of humor and enjoyment encourages employees to reach out to other colleagues, including those who don't think the same way they do, and incorporate a more diverse set of ideas into decision-making. (Hemsath, 1997) Humor in the workplace allows employees to let their guard down and start conversations which may spark innovation. (Bowling, 2003). 


\section{Improved Productivity}

A 2000 report conducted by workforce.com indicated that most workers are not having fun at work. In fact, the predominant feeling was cited as being "stressed out" (22 percent). "Fun" and "happy" trailed behind at 17 and 11 percent respectively. An alarming 48 percent of employees cited backtalk and gossip as the activity most likely to occur in the workplace. "Constant stress, even at a low-grade level, can cut productivity by a huge margin ... If people are spending energy gossiping and backbiting, then that's energy they aren't spending on being productive ("Are you having any fun?", 2000, p. 25)." Encouraging a fun work environment can alleviate feelings of stress and hostility, and therefore contribute to a more productive workforce

Nobody in the industry is more productive than the Southwest employees who have never suffered a strike or a layoff even after the 9/11 tragedy. When you fly with Southwest, you can see that the People of Southwest are enjoying their jobs. Captains and flight attendants joke with passengers, check-in personnel work in casual garb and actually smile at clients, and home office personnel take weeks to prepare for the annual Halloween party.

Another example is the case of Mike Veeck, owner of six minor league baseball teams and author of Fun is Good. Veeck took these losing franchises and turned them into a $\$ 25$ million business by emphasizing customer service and fun. His belief is that the more joyful the experience, the more people will spend on the baseball game experience. That feeling of enjoyment has to start with the employees! (Santosus, 2005, 2)

\section{A FEW CAUTIONS}

While the benefits of having fun at work are significant, there are several notes of caution that must be mentioned. First, humor is a powerful tool. It can create positive results for a company, but it can also create negative situations and feelings that are difficult to counteract. For example, sexual, ethnic, cultural and religious humor has no place in the workforce from a legal and ethical standpoint.

Second, keep in mind that every person may not define humor in the same way. What is humorous to one person may be silly or offensive to another. When trying to create a fun work environment, managers must consider the different manners in which their associates define "fun".

Third, you just can't force someone to have fun at work. If fun is legislated or mandated then the attempts are likely to backfire. Managers should also not create a social life at work that obstructs the social life of employees outside of the workplace. Employees are interested in and deserve to have balance in their lives.

Fourth, fun must not be considered a cure-all to an organization's problems or the sole answer to achieving market competitiveness. Fun is only one aspect of a company's package and must be accompanied with other critical factors such as communication, openness, honesty, trust and clear objectives to be most effective.

\section{CREATING A FUN WORKING ENVIRONMENT}

Most people do know how to have fun. They know what humor is and they know how to have a good time. Employees really just need permission to use humor and have fun in the workplace (Filipczak, 1995). A suggested strategy for building a fun workplace could be called "Be a PAL."

The "Be A PAL" Strategy

\begin{tabular}{|c|c|}
\hline P & Pay for fun \\
\hline A & Allocate time for fun \\
\hline L & Lead the way \\
\hline
\end{tabular}




\section{Pay For Fun}

DWL, a Toronto consulting firm, indicates that fun is an integral part of their culture and they spend the money to prove it. The company gives each employee $\$ 1,000$ each year to do something fun outside of work. The employees bring in pictures of their activities and the associates vote on who had the most fun. The winner is awarded $\$ 5,000$ for the next year's fun activity. The activities include such things as trips, cruises, cooking lessons and fishing camps. By encouraging fun and taking interest in associates' personal interests, the company maintains that morale and retention are strong throughout its workforce (Khirallah, 2001, p. 87).

By the company sponsoring a series of low-cost, fun activities, a strong message is sent to employees. Take, for example, Lipschults, Levin \& Gray, an accounting firm in Illinois, who has found a place for fun in their professional environment. The central office contains a miniature golf course, hula-hoops, playing cards and dartboards. The office has no formal dress code, and the CEO has been seen wearing a gorilla mask at his desk and claims to be a pro at water balloon fights (Filipczak, 1995).

Lawyers and staff who work for Patterson Palmer Hunt Murphy in Saint John, Canada, attend parties in the summer at a partner's summer cottage. The firm also has put together baseball teams as well as the dragon boat team in the Halifax office. Says Peter Forestell, a managing partner of the firm: "The number and quality of fun events has been increasing over the years as we attempt to give priority to collegiality within the firm." (Raymer, 2005, 12)

\section{Allocate Time For Fun}

Some associates feel guilty when taking time for a lunch break. They would certainly feel much worse if they were participating in a parking lot hockey tournament during work hours unless management granted express approval and encouragement. If the company allocates time for the "fun activities," employees are likely to get the message. Sports are commonly used to inject a sense of fun into the workplace. This includes anything from soccer to paintball. The games offer employees a good opportunity to release stress and aggression in a manner that cannot be accomplished in the work environment. Sports can also teach some hidden lessons that do relate to the workplace such as how to resolve conflict and differences amicably at work (Mariotti, 1999).

In conjunction with allocating time, an organization can encourage people to spontaneously meet in the workplace by creating a room for them to gather and collaborate on a less stressful level than the traditional work environment. Some companies have created fun rooms that contain toys, videos and games. Other companies have tranquil rooms with soft seating, aquariums and dim lights. The formula for the rooms may vary. The importance lies in creating space designed with the employees in mind that challenges the expectations of a traditional work atmosphere and encourages fun and all of the benefits it bestows (Gropper \& Kleiner, 1992).

\section{Lead The Way}

Management cannot just send out a memo and expect the workplace to transform into a fun environment. They need to lead by example.

As with any other principle attribute of an organization's culture, the spirit of having fun at work must originate and be wholly supported from the top and then be transmitted all the way to the bottom (Gropper \& Kleiner, 1992, p. 14).

Giving permission to have fun and altering associates' expectations of the atmosphere in the workplace is the first step in creating a fun work environment. There are specific ways to introduce fun into the workplace. One suggestion is to take new employees out to dinner and refrain from talking about work. Get to know the associatestheir interests, family, hobbies, and backgrounds. Also, highlight personal achievements in staff meetings. This exemplifies care on the part of the employer and helps to change expectations of what activities and information work environments should contain (Garber, 2003). Alongside this approach, another suggestion is to increase the quantity and quality of gatherings. This can take the form of parties, meetings, recreational activities, and celebratory events which can be either scheduled or unscheduled. 
The manner in which a business chooses to have fun says something about its culture. One report states that when speaking of fun, employees always mention ice cream and funny clothes. Other companies enjoy April Fools pranks or the creation of annual joke books (Filipczak, 1995). When examining the many ways to have fun at work, a few inspiring examples are worth mentioning.

Southwest Airlines has become famous for its fun work environment and customer atmosphere. The company has maintained an extremely impressive record of long-term profitability and low turnover brought about by offering "positively outrageous service" for a low cost. The company is able to meet its customer service and profitability objectives with its focus on employees. Southwest encourages fun and laughter and is rewarded with high productivity, a friendly staff and unprecedented profitability. "Prospective employees watch a company video of briefcase-toting pilots dancing off a plane to rap music, flight attendants wearing wild costumes and people acting silly at company parties." (Braverman, 1993, 2) The airliner also awards daily acts of recognition for good service, and practical jokes are encouraged even at the corporate office. The fun and good feelings extend to the customers as well. Flight announcements are unusual, such as "There may be 50 ways to leave your lover, but there are only six exits from the plane." (Perrin, 1998, 40). Customers are sometimes surprised by flight attendants hiding in the luggage bins. Herb Kelleher, the former CEO of the company, was known to make an occasional appearance at a Southwest hangar in a flowered hat and purple dress at 2 a.m. (Braverman, 1993). The success of Southwest cannot be denied, and at least part of the competitive advantage is due to its fun work environment.

Amy's Ice Cream in Austin, TX claims a similar work environment. Employees at this company ask the customer if they would like their ice cream thrown. One associate asserts that she can hurl a scoop of ice cream across a four-lane highway although the ice cream may not arrive in the same state it began. (Ice cream that is inedible after throwing is cheerfully replaced). This company creates its fun atmosphere from the beginning of a prospective employee's application process. The application is a paper bag. Individuals are required to do something creative with it and include only their name and number. One applicant brought the bag back attached to a helium balloon that had pictures of the individual's accomplishments and personal interests. Another applicant converted the bag into an aquarium complete with live goldfish. The organization has gained its competitive advantage through its fun atmosphere and lively employees, and works from the beginning to ensure that people who will mesh well with the culture are employed (Filipczak, 1995).

Antics exemplified by these companies may be extreme. Every company is certainly not encouraged to don gorilla masks and throw ice cream at one another. Fun does not have to outrageous in order to be effective. Fun should be appropriate to the culture of the organization, and upon finding the right balance the organization may see powerful results.

\section{CONCLUSION}

Dr. Charles Mayo, founder of the famous clinic, is credited with the inspirational quote, "There is no fun like work." Unfortunately many of us go off to work each day as if it is something to be endured, not enjoyed. Given the fact that a recent U.N. study found that Americans work more days than employees of any other nation, it only makes sense that we should strive to enjoy what we do. On the individual level, employees should seek to follow career paths that will put them into work activities that they enjoy. On the organizational level, however, there is much that can be done to add pleasure to the workplace. The first prerequisite is for the leadership team to believe that fun is an effective strategy for ensuring organizational success. If the leaders are having a good time at work, employees will learn that fun is an organizational value and feel more inclined to join in the activities. Over time, an organizational culture which has open communications and a trusting environment can be strengthened by infusing various structured fun activities and also by allowing employees to have fun on their own. In sum, fun should be considered serious business and creating a fun work environment can be an effective business strategy. 


\section{REFERENCES}

1. All work and no play may be harming your business. (1997). Management Development Review 10(7), 254.

2. Bakke, D.W. (2005). Joy at Work. Seattle: PVG.

3. Bowling, A. (Sep/Oct 2003). Let the games begin! Tough times require fun measures. Rural Telecommunications 22(5), 42.

4. $\quad$ Braverman, T. (July 1993). Training \& Development 47(7), 9.

5. $\quad$ Caudron, S. (June 1992). Humor is healthy in the workplace. Personnel Journal, 71(6), 63.

6. $\quad$ Filipczak, B. (April 1995). Are we having fun yet? Training 32(4), 48.

7. $\quad$ Gropper, C. M. \& Kleiner, B. H. (Nov/Dec 1992). Making work play. Work Study 41(7), 14.

8. Hemsath, D. (1997, Nov/Dec). Are we having fun yet? The Journal for Quality and Participation 20(5), 52.

9. Hulett, Kirk J. (2002, October). Cultivating a good attitude. Advisor Today 97(10), 86.

10. Khirallah, D. R. (2001, January 15). Where having fun really pays. Information Week $8(20)$, 87.

11. Levering, R. and Moskowitz, M. (January 24, 2005). The 100 best companies to work for. Fortune, 151(2), 72-90.

12. Mariotti, J. (1999, March 15). A company that plays together stays together. Industry Week, 248(6), 63.

13. Perrin, S. (1998, February). A serious business. Accountancy 121(1254), 40.

14. Raymer, E. (June 2005). Let the good times roll. National 14(4), 12.

15. Santosus, M. (May 1, 2005). No fun of any kind: We tend to take our jobs—and ourselves-much too seriously, which is why we often don't enjoy either very much. CIO. 18(14), 1.

16. Smith, A.L. (Spring 1997). Are we having fun yet? Business Quarterly, 61(3), 9.

17. Veeck, M. and Williams, P. (2005). Fun is Good: How to Create Joy \& Passion in Your Workplace and Career. Rodale. 